\title{
A LETTER ABOUT THE ARTICLE TITLED 'A STROKE FORM FLUCTUATING IN ACUTE STROKE: CAPSULAR WARNING SYNDROME'
}

\section{'AKUT İNMEDE FLUKTUASYON GÖSTEREN BİR İNME FORMU: KAPSÜLER UYARI SENDROMU' ADLI MAKALE İLE İLGILI MEKTUP}

\author{
Halil ÖNDER \\ Yozgat State Hospital, Neurology Clinic, Yozgat, TURKEY
}

\section{Dear Editor;}

The study of Bostan et al. provides significant information due to demonstration of 3 cases with capsular warning syndrome that is an interesting entity among cerebrovascular diseases. I would like to make some comments in order to clarify the report and the associated subject.

It was mentioned in the report that IV thrombolytic therapy was administered to Case 3 who was hospitalized with transient ischemic attack (TIA) diagnosis, upon worsening 5 hours after the hospitalization. The time range that intravenous thrombolytic therapy is efficient was reported as 4.5 hours following the onset of the symptom in Phase 3, randomized, double-blind, place-controlled studies (1). In this patient, it was observed that there is a time period more than 5 hours between administration of iv-TPA and the onset of the symptoms. Determination of reference time for iv-TPA in these patients could be a significant discussion! It could be anticipated that indicating potential ischemic core using diffusion weighted imaging (DWI) method would provide significant information on determination of stroke onset in these patient sub-groups. Besides, it was understood that the DWI inspection was not performed in pro-symptom early period required to exclude minor stroke diagnosis in the index patient. Arrestingly, as referenced in the report, it was reported that there was no ischemic lesion in the DWI scanned after first three transient neurological symptom attacks in the cases of Fuseya et al. that are thrombolytic therapies conducted before regarding "capsular stroke syndrome" (2). However, the DWI that were repeated due to repeating symptoms after 13 hours following the initial attack provided diffusion restriction complying with lenticulostriate artery area and iv-TPA was successfully administered (80 minutes after the start time of last symptoms) (2). It is further attention grabbing in the other study referenced that there is more than 4.5 hours between first TIA episode and medicine administration time, in four patients who were administered with iv-TPA. It is understood that the authors considered the start time of last neurological attack during iv-TPA administration (3). It is understood that, also in this study, the DWI was not performed after the first attacks of the patients (as in the study of Bostan et al.) and the neuroimaging was performed using CT (3). Considering these information, it can be suggested that it is disputable whether or not the cases handled in the studies of Bostan et al. and Hidalgo et al. satisfy the iv-TPA administration indications in temporal terms. On the other hand, it is understood that a dramatically improvement was ensured in early period in all cases administered with iv-TPA (attack repetition was observed in $3 / 5$ patients during follow-up) and no complication associated with iv-TPA was observed in any case. I am in the opinion that such clinical observations can be discussed on many aspects and can provide very critical perspectives in different sub-scenarios on handling patient and applicability of iv-TPA. 
In further studies in which large case groups that are presented with repeating attacks can be handled, to clarify the issues such as what should be the start-time in iv-TPA administration, the importance of DWI lesion positivity (and predictability) in potential complications and their efficiency in clinical decisions may provide crucial contributions in practice.

\section{REFERENCES}

1. Hacke W, Kaste M, Bluhmki E, Brozman M, Davalos A, Guidetti D, et al. Thrombolysis with alteplase 3 to 4.5 hours after acute ischemic stroke. N Engl J Med. 2008;359(13):1317-29.

2. Fuseya Y, Kawamura M, Matsuda E, Takada K, Watanabe K, Fujitake J, et al. rt-PA with Antithrombotic Therapies in a Case with Capsular Warning Syndrome. Intern Med. 2017;56(4):441-4.

3. Vivanco-Hidalgo RM, Rodriguez-Campello $A$, Ois $A$, Cucurella G, Pont-Sunyer C, Gomis M, et al. Thrombolysis in capsular warning syndrome. Cerebrovasc Dis. 2008;25(5):508-10. 